\title{
Significados de grupo de apoio para familiares na Unidade de Terapia Intensiva Neonatal
}

\author{
Meanings of support group for family members \\ in the neonatal intensive care unit
}

\author{
Aisiane Cedraz Morais ${ }^{1}$ (1) \\ Jéssica Souto Mascarenhas ${ }^{2}$ \\ Jairo Caique de Araujo 3 (1) \\ Manuela de Jesus Souza ${ }^{4}$ (i) \\ Rita da Cruz Amorim 5 (1) \\ Isamara de Sousa Lima ${ }^{6}$ (1)
}

1'Autora para correspondência. Universidade Estadual de Feira de Santana (Feira de Santana). Bahia, Brasil. aisicedraz@hotmail.com 2,3Hospital Estadual da Criança (Feira de Santana). Bahia, Brasil. jeu.soutomm@gmail.com, caiquearaujoenf@gmail.com ${ }^{4}$ Santa Casa de Misericórdia de Feira de Santana (Feira de Santana). Bahia, Brasil. manusouzauefs@gmail.com ${ }^{5}$ Universidade Estadual de Feira de Santana (Feira de Santana). Bahia, Brasil. ritacamor@gmail.com ${ }^{6}$ Residência Multiprofissional em Enfermagem pela Liga Alvaro Bahia contra a Mortalidade Infantil (Feira de Santana). Bahia, Brasil. ysamaralima@hotmail.com

RESUMO | OBJETIVO: analisar o significado que familiares de recém-nascidos internados na Unidade de Terapia Intensiva Neonatal atribuem ao Grupo de Apoio. MÉTODOs: trata-se de um estudo descritivo-exploratório de abordagem qualitativa, desenvolvido na unidade de um hospital público. Participaram sete familiares de recém-nascido internados. Os dados foram coletados em 2017 por meio de entrevista semiestruturada e analisados através da Análise de Conteúdo de Bardin. RESULTADOS: emergiram duas categorias, sendo elas: Grupo de Apoio como cenário de suporte emocional para familiares na unidade e Grupo de Apoio como cenário de informação para familiares na unidade. O Grupo significou um cenário de suporte e cuidado para a família na unidade, sob a forma de suporte emocional associada à formação de vínculos e suporte de informação, surgindo como excelente ferramenta de apoio aos seus membros. CONCLUSÃO: o grupo de Apoio se configurou como espaço de cuidado e suporte para os familiares, através do compartilhamento das experiências, vínculos estabelecidos e informações ofertadas, obtendo efeito positivo no processo de hospitalização dos pacientes e seus familiares, solidificando a humanização entre os profissionais de saúde.

DESCRITORES: Grupos de apoio. Família. Unidade de Terapia Intensiva Neonatal.

\begin{abstract}
OBJECTIVE: to analyze the meaning that family members of newborns admitted to the Neonatal ICU attribute to the Support Group. METHODS: this is a descriptiveexploratory study with a qualitative approach, developed at the unit of a public hospital. Seven family members of newborns admitted to the unit participated. Data were collected in 2017 through semi-structured interviews and analyzed using Bardin's Content Analysis. RESULTS: two categories emerged, namely: Support Group as an emotional support scenario for family members in the unit and Support Group as an information scenario for family members in the unit. The Group meant a scenario of support and care for the family in the unit, in the form of emotional support associated with the formation of bonds and information support, emerging as an excellent support tool for its members. CONCLUSION: the Support group was configured as a space of care and support for family members, through the sharing of experiences, established bonds and information offered, obtaining a positive effect on the process of hospitalization of patients and their families, solidifying the humanization among health professionals.
\end{abstract}

DESCRIPTORS: Self-help groups. Family. Intensive Care Units Neonatal. 


\section{Introdução}

A chegada de um filho traz uma gama de modificações no núcleo familiar; tanto pela incorporação de novas responsabilidades pelos integrantes da família, quanto pela insegurança do nascimento e cuidado de um filho prematuro e/ou de risco ${ }^{1}$.

Quando a criança é encaminhada para a Unidade de Terapia Intensiva Neonatal (UTIN), que consiste em um setor hospitalar de urgência e imediatismo, com assistência voltada para bebês com risco iminente de vida e que, no senso comum, traz uma forte associação com a iminência de morte. Nesse contexto, a família sente-se fragilizada e experiência desapontamento, culpa e medo da perda; o que acarreta em estresse e distanciamento do bebê, prejudicando o apego e vínculo? .

Assim, reconhece-a importância da criação de espaços que propiciem aos familiares a redução do estresse psicológico durante a internação e a formação de uma rede de apoio com outros familiares que vivenciam a mesma experiência e desses com os profissionais de saúde ${ }^{3}$. No cenário da UTIN, o Grupo de Apoio surge como uma proposta de facilitar a aproximação entre pais e equipe multidisciplinar, esclarecer dúvidas sobre o estado geral do bebê, exames e procedimentos realizados, explicação sobre a rotina do serviço, além de permitir a troca de experiências entre os pais 4 .

Esta pesquisa adotou o conceito de família como uma unidade dinâmica, constituída por indivíduos unidos por laços de sangue, de interesse e/ou afetividade, que convivem por um espaço de tempo, construindo uma história de vida 5 .

Mostra-se necessária a abordagem de tal temática, tendo em vista a pouca explanação sobre a temática na literatura e meio acadêmico, bem como seus benefícios para os familiares de crianças hospitalizadas, e, por conseguinte, os efeitos positivos no processo saúde-doença desses núcleos familiares.

Diante disso, tem-se como questão norteadora: Qual o significado que familiares de recém-nascidos hospitalizados na UTIN atribuem ao Grupo de Apoio para a Família?
Com isso, o objetivo desta pesquisa foi analisar o significado que familiares de recém-nascidos internados na Unidade de Terapia Intensiva Neonatal atribuem ao Grupo de Apoio.

\section{Método}

Trata-se de uma pesquisa qualitativa descritivo-exploratória, desenvolvida na UTIN de um hospital no interior da Bahia, tendo como foco o Grupo de Apoio para Família desta unidade.

O Grupo de Apoio desta instituição surgiu com o intuito de promover orientações com diversos temas voltados aos cuidados dos RN, às normas e rotinas da UTIN e do Berçário, bem como o retorno para casa e os aspectos emocionais e cuidados com o próprio acompanhante ${ }^{6}$. Atualmente, desenvolve atividades lúdicas e de suporte aos familiares dos RN internados na UTIN e Berçário, sendo realizado pela equipe de Psicologia e Terapia Ocupacional, uma vez por semana. A média de participação é de 10 a 20 acompanhantes dos referidos setores e a duração é de uma hora e meia.

Os colaboradores da pesquisa foram sete familiares de RN internados na UTIN do hospital; sendo quatro mães, um pai, uma tia e uma avó. Ressalta-se que os critérios de inclusão foram: ser familiares de RN internados na UTIN, que tinham vivenciado pelo menos duas semanas de internamento da criança e que tinham participado de pelo menos dois encontros do Grupo de Apoio; considerando esse período um tempo mínimo para estabelecer significados quanto à participação no Grupo. Não houve limite de idade para esses familiares, visto que há uma predominância de pais menores de idade na UTIN onde o estudo foi realizado. Por outro lado, os critérios de exclusão foram: familiares com deficiência auditiva e da fala; assim como ter algum distúrbio psiquiátrico; pois, essas condições inviabilizariam a coleta de dados, por conta de limitações técnicas da pesquisadora.

Foi utilizada a entrevista semiestruturada como técnica de coleta de dados, no período de outubro a novembro de 2017, mais precisamente às segundas-feiras pela tarde e sextas-feiras pela manhã, utilizado um gravador de voz para armazenar as respectivas 
entrevistas, onde continham em média, 30 minutos de duração. Antecedendo à entrevista, foram coletados dados sócio demográficos sobre o entrevistado e o recém-nascido hospitalizado, com o intuito apenas de conhece-los. Posteriormente, foi realizada a entrevista, que continha as seguintes questões norteadoras: O que você entende sobre Grupo de Apoio? Como você se sente quando participa do Grupo de Apoio? Descreva a sua vivência ao participar do Grupo de Apoio aqui no hospital.

Todos os familiares contatados durante o período de coleta concordaram em participar da pesquisa, sendo posteriormente encaminhados à sala reservada para realização da entrevista, a fim de que fosse garantida a privacidade. Para aproximação no campo, apresentamo-nos à equipe de Psicologia que coordenava o Grupo de Apoio, assim como à coordenadora e equipe de assistência da UTIN, momento era explicada a pesquisa e todo processo de coleta.

A análise dos dados foi feita por meio da Análise de Conteúdo, que consiste em um conjunto de técnicas de análise das comunicações que têm como finalidade o levantamento de indicadores que possibilitem a realização da interferência de conhecimentos ${ }^{7}$.

A categorização aconteceu após leituras exaustivas dos textos transcritos e do recorte de cada unidade de registro das entrevistas, que foram agrupadas em temas por semelhança ou aproximação de conteúdo, focalizando a relação entre os discursos e os objetivos do estudo.

Ressalta-se que a coleta de dados se iniciou após aprovação da pesquisa pelo CEP da universidade, respeitando os critérios da Resolução 466/20128. Ainda, as entrevistas só aconteceram após os colaboradores elegíveis concordarem em participar voluntariamente e assinarem o Termo de Consentimento Livre e Esclarecido ou o Termo de Assentimento Livre e Esclarecido, cujos responsáveis também consentiram através da Autorização dos Responsáveis. Para os códigos de identificação, foi solicitado que cada familiar escolhesse o nome de um sentimento para preservar o anonimato e confidencialidade. Assim, nosso universo foi formado por: Amor, Milagre, Paz, Vitória, Esperança, Gratidão e Emoção.

\section{Resultados e discussão}

Os participantes dessa pesquisa foram em sua predominância: mães das crianças hospitalizadas, com idades entre 16 e 47 anos, se caracterizando como católicas $(57,1 \%)$, solteiras $(71,4 \%)$, negras $(57,1 \%)$, com ensino médico completo $(42,8 \%)$, estudantes (57,1\%), ganhavam menos de um salário mínimo (100\%), tinham apenas um filho $(57,1 \%)$ e moravam com os companheiros $(85,7 \%)$.

$\mathrm{Na}$ análise dos discursos desvelou diversos aspectos sobre os significados que familiares de $\mathrm{RN}$ internados na UTIN atribuem ao Grupo de Apoio para a Família, os quais foram organizados por meio de três categorias, denominadas: Grupo de Apoio como cenário de suporte emocional para familiares na UTIN; Grupo de Apoio como cenário de vínculo entre os familiares da UTI Neonatal; e Grupo de Apoio como cenário de informação para familiares na UTIN.

A ideia de "cenário" nesse contexto se atribui pela sua significação como um local onde ocorre um acontecimento ou uma ação, ou seja, o Grupo é um espaço concreto de suporte para os setores de UTIN, onde se desenrolam ações que têm o suporte e cuidado como significado central para a família.

\section{Grupo de Apoio como cenário de suporte emocio- nal para familiares na UTIN}

Nesta categoria, foram englobadas as falas que traduzem as diferentes formas de suporte emocional que o Grupo de Apoio proporciona para os familiares. Aqui, entendendo suporte emocional como a relação que os indivíduos estabelecem uns com os outros e que servem de auxílio ao outro, levando o indivíduo a crer que é possível encontrar coragem para reagir e ultrapassar possíveis dificuldades no âmbito afetivo?

Os familiares entendem o Grupo como cenário de apoio e acolhimento, que os auxilia a enfrentar o processo de hospitalização na UTIN; o que parece pertinente, pois o acolhimento neste espaço pode se traduzir na forma de escuta e recepção, reconhecendo as necessidades da família e paciente, constituindose como prática de cuidado neste ambiente ${ }^{10}$. 
O que eu entendo sobre de Grupo de Apoio é... Eles ajudam com confortar a gente [...] a gente se sente acolhido e eu gosto muito porque também apoia as pessoas (Amor).

Eu fui bem acolhida, as meninas do Grupo me ajudaram bastante... Toda vez que tinha, iam me chamar e eu me senti muito bem acolhida (Gratidão).

Assim, o apoio foi configurado como suporte e cuidado no cenário do Grupo, traduzindo-se em assistência emocional para a família, diante do difícil processo de hospitalização da criança na UTI Neonatal.

Uma das dificuldades encontradas no contexto do internamento é enfrentar o ambiente fechado do hospital, ainda mais em um setor restrito como a UTIN. Além de carregarem o sofrimento pela condição de internamento da criança, os familiares se deparam com um local rico em diferentes aparelhagens, ruídos e constante movimentação de profissionais que atuam em vigilância e cuidado contínuo.

A privação pelos familiares da relação com sua rede social externa desencadeia sentimentos de ansiedade pelo fato de ficarem fora de suas casas, afastando-se do apoio frequente de amigos e parentes ${ }^{11}$. Sendo assim, foi observado que o Grupo de Apoio é o espaço que proporciona o resgate de pequenos detalhes diários, que fazem a diferença, como momentos de distração; minimizando assim, a angústia de estar no hospital, somada à preocupação pela internação do bebê.

É uma distração para quem vive focado naquele assunto ali, vendo aquele sofrimento todo e a gente ter essa hora, esse momento, é muito importante, pra que faça a gente se retornar mais forte (Vitória).

O que eu participei aqui se diverte. Deixa a gente mais descontraído, esquece até os momentos das tristezas, dos sustos que a gente toma lá na sala (se refere à UTI Neonatal), aquelas máquinas tudo apitando... (Emoção).

Considerando ainda que a UTIN é um setor fechado, emerge a necessidade de interação com elementos do ambiente extra-hospitalar, de acordo com as possibilidades.
Então, pelo fato de eu não conseguir sair do hospital, as mães ficam com a necessidade de ver o ar, de ver o sol, sentir o cheiro... Então, eu acho que o grupo poderia reunir as mães lá fora, por exemplo, no ar livre, em um lugar mais aconchegante, tivesse árvore, flores, pra se sentir melhor, porque aqui dentro a gente se sente muito preso [...]. Dentro do hospital nunca é como lá fora... Assim, então, não levar a gente todas às vezes, mas em um momento, lá fora... Aqui fora, um fora no lugar do hospital, pra gente lembrar que lá fora ainda existe (Gratidão).

Diante desse relato, é interessante refletir sobre atividades que possam ser desenvolvidas no Grupo de Apoio e que proporcionem aos familiares esse contato com o ambiente externo ao hospital, dentro dos limites preconizados pela instituição hospitalar, ou ainda, promover uma roda de conversa dentro do Grupo, orientando à família sobre a possibilidade de outros familiares atuarem como acompanhantes, para que eles consigam sair um pouco do ambiente hospitalar, evitando a sobrecarga e o sofrimento que a internação promove.

A hospitalização da criança na UTIN gera um impacto significativo para os familiares, desencadeando um desequilíbrio emocional e o surgimento de sentimentos como insegurança, frustração, estresse, medo e culpa $^{12}$. Diante disso, essa família passa a procurar apoio emocional, atenção, respeito, apoio social e conselhos para tomada de decisões ${ }^{13}$.

Estas necessidades dos familiares foram minimizadas no Grupo na forma de suporte emocional para a família, servindo para enfrentamentos de crise e ensinamento de novos comportamentos para a aceitação. Os trechos evidenciam o significado desse suporte emocional:

Cheguei assim, cabisbaixo e com medo de enfrentar. Porque é uma nova situação, aí cheguei frustrado assim... E com medo. Depois do grupo, eu sou uma pessoa que tem hoje uma expectativa, que tudo pode. Que tudo a gente consegue (Milagre).

O Grupo está sempre comigo, dando apoio [...]; foi difícil, mas me apoiaram, disseram: "Não fique assim, Deus sabe de todas as coisas"... Aí eles me ajudaram muito mesmo, me apoiaram, me abraçaram, é bom ter

o Grupo porque eles te fortalecem, te ajudam, é algo que te deixa pensar positivo (Amor). 
Observamos que houve modificação de alguns sentimentos negativos vivenciados, onde o Grupo de Apoio auxiliou os familiares a encararem de forma positiva o processo de hospitalização. Foi perceptível que na medida em que os integrantes do Grupo promovem suporte emocional escutando o familiar, se sensibilizando com a sua dor, respeitando suas queixas, ofertando palavras de conforto e estabelecendo confiança com o mesmo. Ele substitui o medo, a angústia, a culpa, a depressão ou até mesmo a raiva, pela resiliência que o auxilia a ir vencendo cada dia da internação de seu bebê, passando a acreditar que estar na UTIN pode não significar o fim da vida, mas sim, a luta para continuar nela.

Assim, configura-se como essencial que os profissionais que atuem em Grupos de Apoio, UTI ou outros setores da saúde, entendam que o suporte emocional perpassa pelos gestos direcionados à família e também ao paciente.

O cuidado emocional é a habilidade de captar o imperceptível e a comunicação não-verbal é um exemplo, se expressando na postura, nas expressões faciais, nos gestos, na aparência e no contato corporal de um dos sujeitos, sendo que tocar afetivamente alguém, dessa forma, é essencial à sua segurança, proteção e autoestima ${ }^{14}$.

Os relatos dos familiares evidenciam a comunicação não verbal e sua importância nas relações interpessoais.

Porque assim, ninguém tem o dom de fazer ninguém se sentir bem o tempo todo. A gente chega aqui, a gente sente no ar, você olha pra cara delas duas (refere-se à psicóloga e terapeuta ocupacional que participam do Grupo), você já se sente bem só pelo sorriso que elas olham para você e dá, então, eu acho que não é todo mundo que tem o dom de fazer isso, acho que é da pessoa mesmo... (Esperança).

Eles tratam a gente e nossos filhos como se fossem deles. É isso que importa. Eu fico observando cada profissional cada um é de uma forma, mas a forma que eles fazem, são muito amorosos. Porque poderia estar ali por estar... (Amor).
Nessa perspectiva, os familiares, dentro de suas particularidades, consideram o Grupo de Apoio na UTIN como um cenário que os oportuniza o cuidado emocional, proporcionando um novo sentido para o enfrentamento da hospitalização de seus bebês, com mais força, esperança e otimismo.

O Grupo vem no sentido de incentivar mesmo, esperar, ter mais fé em Deus, esperança. E confiar na saída aqui, se Deus quiser. A gente não pode dizer que não...

(Emoção).

\section{Grupo de Apoio como cenário de vínculo para familiares na UTIN}

A importância dos laços estabelecidos pelos familiares no Grupo de Apoio, frente ao enfrentamento da hospitalização dos seus bebês na UTIN, mostra que o vínculo se traduz como uma fonte de suporte emocional para eles.

O vínculo 15 expressa uma união com características duradouras, se baseando $\frac{16}{6}$ no aspecto relacional, com influências mútuas entre os indivíduos, podendo ser baseado em amor, conhecimento e reconhecimento, além de um fator emocional que dá significado à relação.

Assim, a partir dos relatos dos familiares, analisamos que as relações interpessoais estabelecidas no Grupo de Apoio culminaram na formação de amizades, que promoveram suporte necessário para driblarem as dificuldades vivenciadas durante a rotina na UTI Neonatal.

No Grupo de Apoio a gente faz amigos... A gente desabafa com eles não tudo o que acontece na vida, mas aquilo que não dá para guardar... (Amor).

Eu tinha conhecidos lá da UTI Neonatal, mas depois do Grupo foi bom porque a gente passa a conhecer mais as pessoas assim... Fiz amizades não só com as pessoas da UTI Neonatal, mas com de outras "UTI" (Vitória).

Esses relatos evidenciam que a partir do momento em que o Grupo de Apoio permite a junção de diferentes familiares com os profissionais que estão à frente do Grupo, relações interpessoais vão se estabelecendo e culminando na formação do vínculo. 
O compartilhamento de experiências entre os familiares, no âmbito do Grupo, permite que as mesmas entendam que não estão sozinhas, o que acaba alimentando a esperança de enfrentamento das dificuldades. Este aspecto foi evidenciado na fala de um familiar:

Eu sou tímida, mas eu procuro estar no Grupo, a gente precisa de todo mundo, a gente não pode se afastar, que aqui tem hora que a gente fica só, mas, numa hora assim, que a gente tá no desespero, aí tem uma amiga do Grupo que conversa, fala do que viveu, já alegra a gente, já dá mais esperança, eu não tenho mais como sair desse grupo... (Emoção).

A relação de amizade estabelecida no Grupo de Apoio permite que os familiares o configurem como um espaço familiar, propiciando a aprendizagem de convivência com diferentes pessoas, com vivências diversas frente ao processo de internação do bebê na UTIN, possibilitando apoio significativo frente à rotina vivenciada neste setor.

Os discursos desses familiares revelam esta configuração do Grupo como um espaço familiar:

Se eu não tivesse o apoio do Grupo aqui... porque eu estou longe de tudo, distante da família, de pai, de mãe, de tudo... E aí eles me apoiam muito, a gente toma café da manhã "junto", almoça "junto", conversa... Não é a nossa casa sabe? Mas acaba se tornando porque a gente se sente acolhido, é isso que importa e eu só tenho a agradecer e muito [...] devido a mim não estar em casa, eles acabam sendo família, eles anotam telefone... (Amor).

O sentimento de pertencimento de um indivíduo, como um dos elementos referentes ao vínculo, é intitulado como aquilo que o caracteriza como parte íntima de um específico contexto ou grupo, e relaciona-se com o vínculo por ofertar o estabelecimento de relações, troca e laços de cuidado ${ }^{17}$.

Um fator importante e advindo do vínculo formado no Grupo de Apoio foi o estreitamento dos laços de amizade, mesmo fora do ambiente hospitalar, através de recursos tecnológicos que propiciam o contato entre aqueles que receberam alta e os que ainda continuam na UTIN.
Esse Grupo promove muitas amizades; quando uma tem alta, já pega o "zap" (refere-se ao aplicativo telefônico de mensagens instantâneas "whatsapp"),

ficam mandando as fotos da casa, de onde mora, "é" como irmãos aqui no hospital mesmo... (Emoção).

Isso evidencia a importância do contato entre os familiares além da rotina do hospital, o que pode perpetuar as amizades feitas através do Grupo, o que garante a qualidade e confiança das relações de amizade vivenciadas, pois demonstra a riqueza dos vínculos estabelecidos.

Essa rede de apoio mútuo e familiar ofertada pelo Grupo de Apoio confirma o altruísmo como um efeito terapêutico para os familiares na UTIN. O altruísmo refere-se à tendência ou inclinação que desperta alguém a se preocupar com seus semelhantes, e, sendo o Grupo um espaço coeso, é comum o afilamento de laços através de telefonemas, visitas e auxílio mútuo nos momentos de dificuldade, sendo um benefício terapêutico para a família que vivencia o processo de internamento do bebê na UTI Neonatal18.

Apesar de outros discursos já demonstrados aqui possuírem teor altruísta, o relato de um familiar em específico - evidencia mais explicitamente o seu significado:

Olha, eu acho que depois do Grupo, eu me tornei outra pessoa, comecei a ver além do que eu via, porque eu nunca fui uma pessoa egoísta, mas assim, eu só olhava até a minha expansão [...] Grupo me fez olhar além do que eu estava vendo [...] Com o passar do tempo, isso me fez ajudar outras pessoas que estão no mesmo estado que eu, eu vou dando força, porque eu fico imaginando como é que a pessoa está se sentindo, porque eu passei por isso. (Esperança).

A fala de Esperança revela que o Grupo possibilitou uma forma altruísta de ver o mundo e as pessoas, que repercutiu em suas atitudes. Ressaltamos ainda que o Grupo de Apoio pode estreitar o vínculo entre o familiar e o paciente. Neste caso, a fala de Gratidão expressa como o Grupo ajudou na formação/manutenção do vínculo com sua filha na UTIN. 
O grupo auxiliou no desenvolvimento meu e da minha filha (...) Então, eu passei a ajudar mais minha filha, porque antes eu ficava acuada, ficava com medo, eu estava triste com tudo e depois do Grupo eu não tive mais medo, fiquei mais forte e tive mais vontade de ajudar ela, cada vez mais... (Gratidão).

É possível perceber que o relato do familiar evidencia sentimentos emergentes no ambiente da UTIN: o medo dos familiares em estabelecerem vínculo com o bebê; muitas vezes pelo excesso de aparelhagens, pelo sofrimento vivenciado ou até pela insuficiência de incentivo por parte dos profissionais que atuam neste setor. Percebemos que a tristeza emergida pelo internamento da filha na UTIN levou Gratidão a ter receio de estabelecer contato com a mesma e que a sua participação no Grupo de Apoio promoveu estímulo e fortalecimento emocional, culminando com a formação de vínculo entre mãe e filha.

Assim, a participação no Grupo foi significativa na vida do familiar, pois permitiu que ele driblasse a tristeza sentida pelo internamento do seu bebê na UTIN e, por conseguinte, o medo de estar perto dele, o que acabou fortalecendo-o para assumir um papel de referência de cuidado ao mesmo, baseado no vínculo e no afeto.

\section{Grupo de apoio como cenário de (des) informa- ção para familiares na UTIN}

O fornecimento de informações pelo Grupo possibilita aos familiares a percepção real do que estão vivendo, através do conhecimento de dados mais concretos sobre o problema, acarretando em um ambiente que propicia esclarecimento de dúvidas e ganho de orientações indispensáveis ${ }^{19}$.

A realização de atividades no contexto do Grupo de Apoio tem como finalidade ${ }^{19}$ mobilizar seus integrantes para objetivos determinados, tais como orientações verbais, recursos lúdicos (teatro, brincadeiras, pinturas), construção de cartazes e folhetos, dinâmicas, entre outros, fortalecendo o espaço como um cenário de construção e compartilhamento de ideias. Além disso, ter suporte de informação funciona indiretamente, como apoio emocional, pois, o esclarecimento de questões técnicas e relacionadas ao contexto da UTIN, promove empoderamento aos familiares para lidar com essa situação.

Os discursos revelaram o Grupo de Apoio como um cenário propiciador de informações, por meio de atividades como dinâmicas, brincadeiras e sessões de filme.

Eles trabalham com várias atividades, cada dia, cada semana, é uma novidade... A gente acaba aprendendo... Tipo assim, a atividade do Outubro

Rosa, esse negócio que a gente não sabe, acaba aprendendo e passa pro outro (Milagre).

Eu aprendi com aquela atividade do cordãozinho, significava que a gente não é diferente um do outro, cada um teu seu objetivo de sair com sua criancinha sã e salva (Emoção).

Os familiares denotam que assimilaram as mensagens objetivadas pelas atividades lúdicas do Grupo, expressando o aumento de seus conhecimentos e do interesse pela busca e compartilhamento de informações.

Salienta-se que os familiares devem ser atendidos em suas preocupações, recebendo informações sobre o estado de saúde, tratamento e equipamentos utilizados no bebê, já que possuem aflição, por conta de uma situação não compreendida pelos pais. Assim, sinalizaram a necessidade do Grupo de Apoio abordar estas questões:

Eu acho que deveria explorar mais informações sobre a UTI assim... fala muito pouco no Grupo; porque tem horas que a gente sai estressada, chorando, a máquina fica apitando, eu não sei o que está acontecendo com a criança, fico estressada, com medo do que pode acontecer assim... (Emoção).

Olha, até o momento eu não vi informação sobre as coisas de lá (referindo-se à UTIN)... Eu acho muito importante que dê, eu já até dei sugestão sabe? Porque a gente não entende tudo não, fica preocupado com o que pode acontecer (Esperança).

Desta forma, o Grupo de Apoio pode ser um espaço para abordar questões específicas, vivenciadas pelos familiares e até mesmo ter sessões elaboradas a partir das demandas destes pais/família. 
Nesse ponto, vale salientar a importância da inter/ multidisciplinaridade no Grupo, pois a presença de diferentes profissionais em suas sessões culminaria em divulgações de informações específicas de suas atuações na UTIN, o que possibilitaria numa abordagem de conhecimentos diversos, configurando um caráter mais informativo a esse cenário e, consequentemente, auxiliando a sanar as dúvidas que surgem por parte dos familiares quanto à condição clínica e práticas intervencionistas realizadas em seus bebês neste setor.

Nota-se como limitação desse estudo a pouca abrangência em materiais teóricos relacionados à temática, interferindo em melhor análise sobre as possibilidades, problemáticas e consequências de tais grupos; ao tempo em que indica-se uma discussão que possa permear as diferentes formações acadêmicas na área da Saúde, uma vez que compreendemos o Grupo de Apoio como estratégia de cuidado humanizado.

\section{Conclusão}

O Grupo de Apoio se apresenta como um cenário de suporte e cuidado para os familiares na UTIN, minimizando o sentimento de angústia e privação da liberdade desencadeado pela hospitalização; ainda que este estudo tenha como limitação ter feito a investigação apenas em um setor.

Além do suporte emocional, as informações veiculadas pelas atividades lúdicas foram benéficas, pelo fato de alguns familiares relatarem a necessidade de ampliação dos seus conhecimentos. Porém, o Grupo de Apoio não trouxe ainda informações específicas da assistência e condição clínica do bebê na UTIN. Assim, reforça-se que a equipe multidisciplinar atue em conjunto no Grupo de Apoio, suscitando entre os familiares suas dúvidas, questionamentos a respeito da condição clínica do bebê ou outros elementos da unidade de internação. Desta forma, ampliar-se-á a configuração do Grupo de Apoio como um cenário que possibilita uma posição de protagonismo para os familiares, na medida em que os temas das reuniões sejam escolhidos por eles.
Destaca-se que o Grupo de Apoio pelos familiares seja uma estratégia ampliada para diversos setores e instituições, nos diferentes níveis de assistência à saúde; envolvendo pacientes, familiares e profissionais na inter e multidisciplinaridade.

Por fim, entendemos que este estudo dá visibilidade ao Grupo como um efeito terapêutico aos familiares dos bebês internados na UTIN, reforçando a necessidade do olhar sensível para a família neste setor.

\section{Contribuições dos autores}

Morais AC participou da concepção, delineamento, análise dos dados da pesquisa, interpretação dos resultados e redação do artigo científico. Mascarenhas JS participou da concepção, delineamento, busca e análise dos dados da pesquisa, interpretação dos resultados, redação do artigo científico. Araújo JC, Souza MJ, Amorim RC e Lima IS participaram da análise dos dados da pesquisa, interpretação dos resultados, redação do artigo científico.

\section{Conflitos de interesses}

Nenhum conflito financeiro, legal ou político envolvendo terceiros (governo, empresas e fundações privadas, etc.) foi declarado para nenhum aspecto do trabalho submetido (incluindo, mas não se limitando a subvenções e financiamentos, participação em conselho consultivo, desenho de estudo, preparação de manuscrito, análise estatística, etc.).

\section{Referências}

1. Carvalho LS, Pereira CMC. As reações psicológicas dos pais frente à hospitalização do bebê prematuro na UTI neonatal. Rev SBPH. 2017;20(2):101-22.

2. Campos CA, Silva LB, Bernardes JS, Soares ALC, Ferreira SMS. Desafios da comunicação em Unidade de Terapia Intensiva Neonatal para profissionais e usuários. Saúde Debate. 2017;41(n. esp):165-74. doi: 10.1590/0103-11042017S214

3. Azevêdo AVS, Lançoni Junior AC, Crepaldi MA. Interação equipe de enfermagem, família, e criança hospitalizada: revisão integrativa. Ciência \& Saúde Coletiva. 2017;22(11):3653-3666. doi: $\underline{10.1590 / 1413-812320172211.26362015}$ 
4. Dadalto ECV, Rosa EM. Vivências e Expectativas de Mães com Recém nascidos Pré-termo Internados em Unidade de Terapia Intensiva Neonatal. Estud Pesqui Psicol. 2015;15(3):814-834.

5. Secretaria de Saúde do Estado da Bahia - SESAB. Hec realiza "grupo aconchego" com acompanhantes [Internet]. 2016. Disponível em: http://www.saude.ba.gov.br/2015/10/26/hecrealiza-qgrupo-aconchegoq-com-acompanhantes/

6. Bardin L. Análise de conteúdo. São Paulo: Edições 70; 2010.

7. Ministério da Saúde. Conselho Nacional de Saúde. Resolução $\mathrm{n}^{\circ}$. 466 de 12 de dezembro de 2012. Diretrizes e Normas Regulamentadoras de Pesquisas em Seres Humanos [Internet]. 2012. Disponível em: https://bvsms.saude.gov.br/bvs/saudelegis/ cns/2013/res0466_12_12_2012.html

8. Siqueira MMM. Construção e validação da escala de percepção de suporte social. Psicologia em estudo. 2018;13(2):381-88. doi: 10.1590/S1413-73722008000200021

9. Rodrigues AC, Calegari T. Humanização da assistência na unidade de terapia intensiva pediátrica: perspectiva da equipe de enfermagem. Rev Min Enferm. 2016;20:e933. doi: 10.5935/1415$\underline{2762.20160003}$

10. Amaral LFP, Calegari T. Humanização da assistência de enfermagem à família na unidade de terapia intensiva pediátrica. Cogitare Enferm. 2016;21(3):01-09. doi: 10.5380/ce.v21i3.44519

11. Gonçalves KG, Figueiredo JR, Oliveira SX, Davim RMB, Camboim JCA, Camboim FEF. Criança hospitalizada e equipe de enfermagem: opinião de acompanhantes. Rev Enferm. 2017;11(6):2586-93. doi: 10.5205/reuol.9799-86079-1RV.1106sup201713
12. Serafim CM, Lima CB. Unidade de Terapia Intensiva Pediátrica, sob o olhar do acompanhante da criança hospitalizada. Temas em Saúde. 2016;16(3):381-403.

13. Balbino FS, Yamanaka Cl, Balieiro MMFG, Mandetta MA. Grupo de apoio aos pais como uma experiência transformadora para a família em unidade neonatal. Esc Anna Nery. 2015;19(2): 297-302. doi: $10.5935 / 1414-8145.20150040$

14. Santos PM, Silva LF, Depianti JRB, Cursino EG, Ribeiro CA. Os cuidados de enfermagem na percepção da criança hospitalizada. Rev Bras Enferm. 2016;69(4):646-53. doi: 10.1590/0034-

\section{$\underline{7167.2016690405 i}$}

15. Marchetti D, Moreira MC. Vivências da prematuridade: a aceitação do filho real pressupõe a desconstrução do bebê imaginário?. Rev Psicol Saúde. 2015;7(1):82-9. doi: 10.20435/pssa. v7i1.408

16. Duarte MV, Santos JR, Reis CB. Enfrentamento dos familiares ou responsáveis diante da hospitalização da criança. Enfermagem Brasil. 2015;14(1):36-44.

17. Barroso VG, Mattos CM. Sentimento de pertencimento na constituição do vínculo em uma autogestão de saúde suplementar. Cienc Cuid Saude. 2016;15(4):616-23. doi: 10.4025/ cienccuidsaude.v15i4.33385

18. Ruse M. A Darwinian Naturalist's Perspective on Altruism. Nova York: Oxford University Press; 2002.

19. Pinto JP, Ribeiro CA, Pettengill MM, Balieiro MMFG. Cuidado centrado na família e sua aplicação na enfermagem pediátrica. Rev Bras Enferm. 2010;63(1). doi: 10.1590/S003471672010000100022 